\title{
Study of a Water-Energy Integrated System: Challenges of Prototyping
}

\author{
Ana Rita Silva ${ }^{1,2}$ \\ ${ }^{1}$ ICOVI, EM - \\ Infraestruturas e \\ Concessões da \\ Covilhã \\ Covilhã, Portugal \\ anarita.silva@icovi. \\ $\mathrm{pt}$ \\ ${ }^{2}$ Department of \\ Electromechanical \\ Engineering \\ University of Beira \\ Interior \\ Covilhã, Portugal \\ ana.rita.silva@ubi.pt
}

\author{
Fernando Santos ${ }^{2,3}$ \\ ${ }^{2}$ Department of \\ Electromechanical \\ Engineering \\ ${ }^{3}$ Centre for \\ Mechanical and \\ Aerospace Science \\ and Technologies \\ University of Beira \\ Interior \\ Covilhã, Portugal \\ bigares@ubi.pt
}

\author{
António Espírito- \\ Santo $^{2}$ \\ ${ }^{2}$ Department of \\ Electromechanical \\ Engineering \\ University of Beira \\ Interior \\ Covilhã, Portugal \\ aes@ubi.pt
}

\author{
José Páscoa ${ }^{2,3}$ \\ Marques \\ ${ }^{2}$ Department of \\ Electromechanical \\ Engineering \\ ${ }^{3}$ Centre for \\ Mechanical and \\ Aerospace Science \\ and Technologies \\ University of Beira \\ Interior \\ Covilhã, Portugal \\ pascoa@ubi.pt
}

\author{
Cristina Fael ${ }^{4,5}$ \\ ${ }^{4}$ Departamento de \\ Engenharia Civil e \\ Arquitetura \\ ${ }^{5}$ Centre of Materials \\ and Building \\ Technologies \\ cmsf@ubi.pt
}

\begin{abstract}
In a society where Energy and Water walk side by side in practically all sectors of activity, it becomes necessary to analyze them from a productive, economic and sustainable point of view. Although independently developed and regulated, it is known that water needs energy and energy needs water. The increasing demand for energy and its exponential trend will have repercussions at all levels in the short term. and consequently, will increase the strain on freshwater resources. All these concerns and associated decision-making policies create an opportunity to improve the management of both sectors. There is an urgent need to improve the water-energy system and reduce energy consumption, using advanced technological changes and an optimized management strategy, leading to a more sustainable future. By improving the efficiency of water and energy use through integrated smart strategies, there are very positive repercussions on savings and impact on the local economy, especially in decentralized cases. The present paper aims to address the theme of the nexus of water-energy in the scope of promoting alternatives of management and development of integrated systems and study the dynamics of the development of the theoretical concept vs. prototyping in case of urban context and real environment.
\end{abstract}

Keywords - Renewable Energy, Maximization of Energy, Optimization of Integrated Systems.

\section{INTRODUCTION AND BACKGROUND}

Despite being considered a renewable and abundant resource, water is not always available for human consumption in the quality, quantity, time and place required and, therefore, its availability can directly affect any energy system. Rapid human growth, centralized industrialization and the improvement of society's lifestyle are the main factors that contribute to the increasing demand for water in most regions of the world. On the other hand, the current and long-overdue energy crisis is and exponentially will continue to be a result of the increasing use of primary sources and the necessity of their transformation to obtain energy, and which

Acknowledgment to FCT, The Portuguese Funding Agency and Foundation for Science and Technology. tends to disobey natural terrestrial renewal, being increasingly crucial for the normal functioning of all human activities. Whether for economic, political or social reasons, it is well known that in technological terms, the energy sector evolves rapidly. Numerous solutions are being pursued to ensure that global energy efficiency increases and contributes to long-term sustainable exploitation while at the same time creating beneficial synergies for water and energy services. The use of unconventional oil and gas, the liquefied gas that increases the supply flexibility and large quantities of renewable sources are being integrated into the system [1]. These measures may not be carried out in some situations if resource competitiveness is more significant than the sustainable objectives of the water-energy link.

Integrated water and energy management systems are directly related to the concept of smart cities, whether in an urban or rural environment and consequently associated with the Living Lab (LL) concept. According to the DirectorateGeneral for Information Society and Media of the European Communities [2], "Living Lab is an open, user-oriented innovation ecosystem based on a government-citizengovernment partnership that allows users to be active in the process development and innovation. Bringing users into the creative process in order to better discover new and emerging behaviors and patterns; bridging the innovation gap between technological development and the acceptance of new products and services involving all relevant stakeholders through partnerships in business, citizens and government; and allowing the early assessment of the socioeconomic implications of new technology solutions, demonstrating the validity of innovative services and business models "represent some of the solutions/strategies between the implementation process of Living Labs.

ENoLL (European Network of Living Labs) [3] also describes LL as "user-centered, open innovation ecosystems based on a systematic approach to co-creation, integrating research and innovation processes into communities and environments of real life". In practice, Living Labs put citizens at the center of innovation and demonstrate the ability to better shape the opportunities offered by new ICT 
concepts and solutions for the specific needs and aspirations of local contexts and cultures.

It is indeed a sustained fact that the work developed in Living Labs communities has a significant impact on the policy of technological innovation, moving away from linear research activities and towards open innovation. In this sense, the practical case study described in this document, besides stimulating the union of efforts between public and private entities, overcomes some knowledge gaps and contributes to the scientific advance of the subject, and additionally - after the validation of its installation and operation by the team - will be used in several perspectives of future use, namely:

- The scope of the optimization of the system in relation to the consumed energy vs produced energy (selfsufficiency);

- Expansion to other potential locations of the city's public water supply network and contribution to further expansion to networks managed by different management entities (inside and outside Portugal);

- The use of similar systems in rural context;

- Continuous research throughout the useful life of the equipment, from the monitoring of the ratio of produced/consumed energy to the implementation of improvements of the applied instrumentation and mode of operation of the system;

- The collection of an extensive database for statistical analysis to be incorporated into research projects that need it.

Therefore, this document is structured as follows: Section II provides an overview of the integration and management of water and energy systems, Section III presents the concept development in urban context, Section IV exposes the restrictions to the implementation of the developed concept, Section V shows the configuration of the pilot project to be installed in a real environment and in urban context, Section VI describes the monitoring and supervision system of the prototype, and finally the last section presents the conclusions.

\section{WATER AND ENERGY INTEGRATED SYSTEMS: CHALLENGES AND OPPORTUNITIES}

According to what has been said previously, the increase in demand for energy and water has negative repercussions and will increase the tension mainly in freshwater resources, with the agricultural and industrial sectors the most affected, as it is nowadays. The first sector covers about $70 \%$ of the world's water extractions and the production of food products and water supply networks account for approximately $30 \%$ of total energy consumption [4]. The industrial sector uses approx. $37 \%$ of global primary energy use and uses less water proportionally [5]. The report produced by the World Energy Council in 2010, Water for Energy, assesses the scale of the problem and reveals the process steps needed to ensure the sustainability of the integrated energy-water system and that water is available for all energy demand, including data on water requirements in other energy technologies and on regional water needs. The report concludes that it is probably possible to meet future demand for water in energy production, but it needs to be included in decision-making policy, as well as in the paradigm of international cooperation between governments, between companies, and between governments and companies [6]. The use of alternative water resources, such as seawater or wastewater, offers great potential to reduce the demand for fresh water [4]. Already in the field of renewable energy sources, such as wind, photovoltaic and geothermal, although they are marginal on a global scale, they can contribute substantially to energy supply and to the reduction of demand for fresh water. UNESCO reveals that although hydroelectric production does not consume water, it needs to store it in large quantities so that it may or may not affect the availability of the resource for other uses [7]. The same document also reveals that in terms of water impact, solar and wind energy are the most sustainable types of energy production. However, in most cases, the intermittent service provided by wind and solar must be compensated for by other sources of energy which always require large amounts of water to maintain the load balance. Despite the increase in proportion to traditional energy production, renewables are still underdeveloped [4]. Although competitive and unlike hydroelectric and geothermal, wind and solar energy remain an expensive alternative and require political support to promote its installation in most countries. Today they account for only $3 \%$ of global energy. Although expected to grow rapidly in the coming decades, they are unlikely to account for more than $10 \%$ of electricity production by the year 2035 [1]. In addition of being a very viable alternative to thermal energy and its abuse of water resources, renewable energy has more benefits, such as increasing energy security and diversity, reducing greenhouse gas emissions and local pollution, the contribution to sustainable growth and mini-network or off-grid solutions that offer less expensive systems than the extension of the conventional network to rural areas [8]. However, despite the exception of areas where water is scarce, the availability and impacts of water exploration for other energy production processes are very rarely taken into account in the study of energy and policy formulations, water and energy have historically been regulated and managed separately [9], which has led to the adoption of unsustainable practices that currently compromise the availability of water resources. There are, however, and as has been said before, some measures to be considered and which create beneficial synergies to water and energy production services, such as: innovative studies of integrated water and renewable energy systems, combined energy and desalination plants, combined heat and power plants, the use of alternative water sources for infrastructure cooling, and even energy recovery through wastewater [10]. Co-operation between decision-makers in electricity networks and water supply institutions operating in the same region together with the national government will be necessary for improved and efficient water and energy management. Such cooperation can also benefit and enable the sustainable use of water for other types of energy production in the region. From the point of view of sustainable development, the limitations and availability of water for energy production will be critical factors in achieving the SDG (Sustainable Development Goals) of energy. Even if electricity production through the wind or photovoltaic system doubled, there would still be a strong need to use water to achieve universal access to sustainable and viable services and support global economic and industrial growth. [7]. Mark Jacobson and Mark Delucchi published two articles in the context of the development of the concept in urban context.: "Providing all global energy with wind, water, and solar power, Part I: Technologies, energy resources, quantities and areas of infrastructure, and materials" and "Part II: Reliability, system and transmission 
costs, and policies "[11], [12]. In the first part, they discuss the characteristics of the WWS (Wind - Water - Solar) energy system, current and future demand, availability of WWS energy sources, number of WWS devices required, and material and area requirements. Part II addresses the variability, economics, and policies of WWS energy. It is estimated that approx. 3800000 of $5 \mathrm{MW}$ wind turbines, 49 000 of $300 \mathrm{MW}$ concentrated solar power plants, 40000 of $300 \mathrm{MW}$ solar PV plants, $1700000000 \mathrm{PV}$ systems on roofs of $3 \mathrm{~kW}, 5350$ of $100 \mathrm{MW}$ geothermal power stations, 270 new $1300 \mathrm{MW}$ hydroelectric plants, 720000 wave power generation devices of $0.75 \mathrm{MW}$ and 490000 of $1 \mathrm{MW}$ marine turbines are needed to sustain a WWS world in the year 2030 for all purposes. Such WWS infrastructures reduce world electricity demand by $30 \%$ and require only about $0.41 \%$ and $0.59 \%$ more land for footprint and space, respectively. The same article also suggests producing all the world's energy through the WWS system by the year 2030 and replacing the pre-existing energy by the year 2050. It should be noted that the only barriers to the described process are only of a social and political nature, and not technological or economic. The cost of energy in a WWS world would be very similar to the system used today. In 2014 and under the nexus water-energy, the United Nations have launched a publication where they suggest that the public policy response to the connection between water and energy requires a hierarchy of actions designed to create an environment conducive to the implementation of the necessary changes to the development of water and energy resources, which focus on the following points [4]: development of coherent policies; legal and institutional structures to promote such coherence; ensuring the reliability of the data and statistics collected for monitoring decisionmaking; awareness of the problem; support innovation and research in the field of technological development; ensure that funding is available; allow markets and companies to develop around the problem. The interdependence between energy and water is nowadays of major importance in all the analyzed literature on the subject, and even then, research and the existence of case studies is very limited.

\section{Development of The CONCEPT IN URBAn CONTEXT}

In the scope of the present study, it is intended to implement an integrated water and energy management system in an urban context in a section of a pipeline of the municipal water supply system of Covilhã, in Portugal. First, it is necessary to develop the concept in theoretical terms of the problem. Fig. 1 represents a hypothetical and ideal scenario of a set of blocks (buildings/villages/cities) provided with renewable energy and united by an integrated management center, a concept that will be extrapolated to the development of the concept and of the prototype in urban context and within the scope of the present case study, in the city's Botanical Garden. The process of developing, designing and implementing an integrated system according to Fig. 2, besides being iterative, is extremely complex, requiring a coordinated and organized preliminary plan. In addition to identifying all the involved variables, possible scenarios, and associated constraints, it is necessary to go through several stages: the identification and characterization of the site, the pre-feasibility and feasibility studies, and finally the detailed design of the integrated energy recovery system [13].

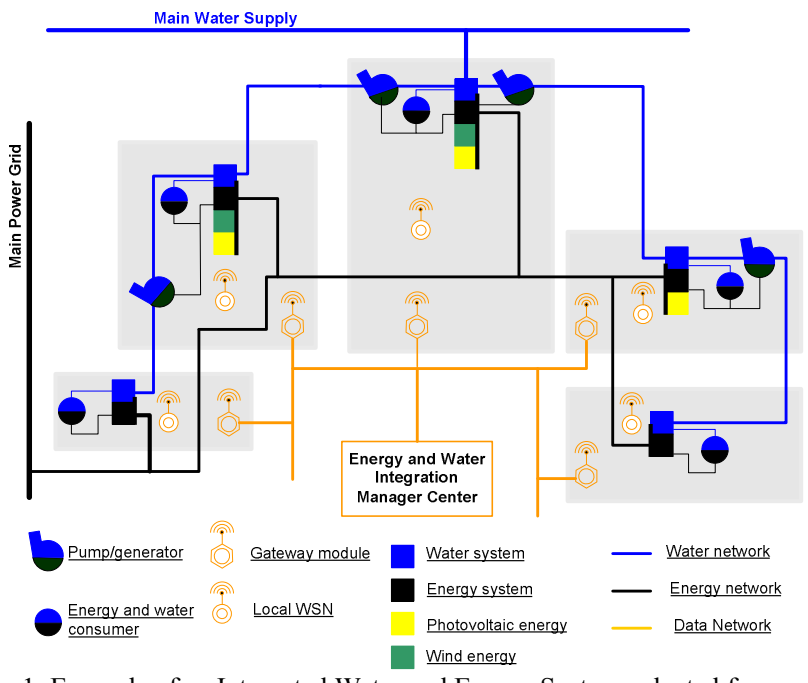

Fig. 1: Example of an Integrated Water and Energy System, adapted from [13].

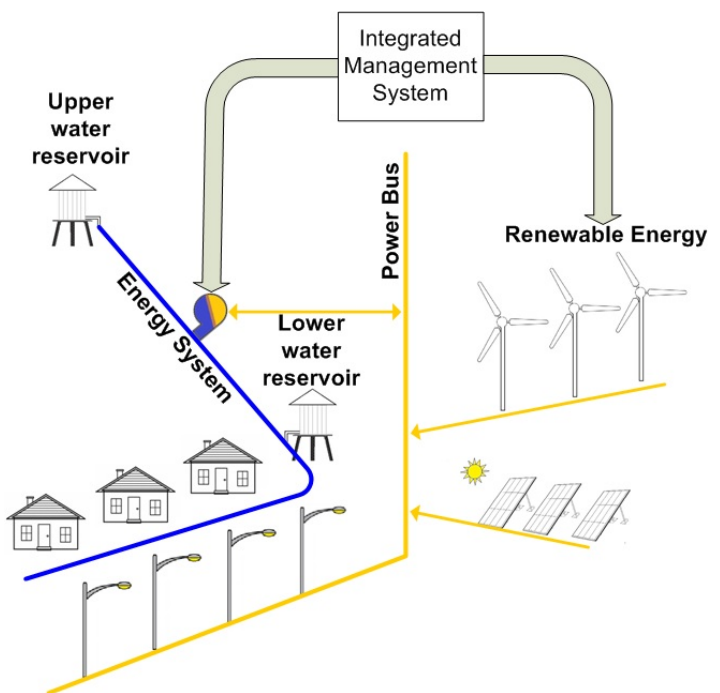

Fig. 2: Schematic drawing of an integrated water and energy management system in an urban context to be implemented in the city of Covilhã, Portugal [14].

Currently, an optimization model of interaction between different types of energy resources in a real environment is being analyzed. In the first phase, an adductor pipeline (125 meters in length and nominal diameter of $200 \mathrm{~mm}$ ) between both reservoirs located in the Park is being analyzed together with the ideal conditions of solar radiation and wind intensity. In developing a theoretical concept of an integrated water and energy system, it is necessary to face energy needs with various types of renewable energy sources, with the help of conventional energy (if necessary), energy storage and an optimization and management center. In order to do this, the possible factors and sets of primary variables are presented:

\section{- Water factor:}

- Inputs and Outputs - Water supply for consumers; Irrigation; origin of water (dam, mines, wells, etc);

- Dimensioning of equipment for energy use Available flow; useful net head; Size/capacity of the reservoirs; Distance between reservoirs; Continuity of flow or not;

- Equipment specifications (PAT/hydraulic turbine) Power; performance curve; Nominal diameter; Rotation speed. 
- Wind factor:

- Sizing of energy recovery equipment - Average wind speed/intensity; NEP (number of hours equivalent to nominal power);

- Equipment Specifications (wind turbine) - Flat section area; Wind speed; Mass ( $\rho . A . v, \mathrm{~kg} / \mathrm{s}$ ); type of wind turbine; Turbine efficiency.

- Sun Factor:

- Sizing of energy recovery equipment - Annual insulation; Horizontal solar irradiation; Environment temperature;

- Panel specifications; Module dimensions; Area of implementation; Panel temperature coefficients and parameters (nominal operating cell temperature, maximum system voltage, reverse current limit, maximum fuse rating in series, connector types, application category, wind and snow front load, load wind rear, among others); Electrical characteristics and performance (module efficiency, open circuit voltage, among others); Power panel; cell type; Number of cells; Frame material type; Voltage vs Current curve $\left[25^{\circ} \mathrm{C}\right.$ or $\left.1000 \mathrm{~W} / \mathrm{m}^{2}\right]$.

- Auxiliary/Conventional sources of Energy Factor:

- Equipment specifications - Diesel engines.

- Energy storage factor:

- Capacity of water reservoirs - Distance and pumping height; Powered by battery.

- Factor of Management system and control center:

- Telemanagement devices; Wireless network and smart sensors.

The energy requirements of an Integrated Water and Energy System can be met through different scenarios and combinations of renewable energy sources such as wind, sun, and water. However, in off-grid situations (outside the conventional grid), the stochastic character of these sources make it necessary to include conventional elements, such as diesel engines, combined with a power storage unit, and which type of system is commonly referred to as a hybrid. Any situation that requires more than just one renewable energy source to meet the needs of a given load requires an EMS (Energy Management Strategy), which the main objective is to find the balance between the production of renewable energy of unpredictable supply and the fluctuating energy demand. It can also be said that the transitions between the different states of the integrated system are attributed to the following scenarios (applied to the presented case study) and respective combinations: Variation in the production of renewable energy; Variation in water consumption; Variation in energy consumption; Variation of energy and water storage levels in reservoirs; Integrated system layout (chosen type of equipment/installed infrastructure).

\section{CONSTRAINTS ON THE IMPLEMENTATION OF THE DEVELOPED CONCEPT}

As well as the definition of all the variables and scenarios, it is of great importance to define the constraints related to the implementation and development of waterenergy integrated systems. In regard to this study case, and in terms of morphology, operation mode, financial, judicial and environmental scope, there are a number of constraints associated with the process of the prototype development, namely:
The place of implementation: The first constraint associated with the installation of the prototype is the boundary of the place of implementation. As previously mentioned, the prototype will be installed in the Botanical Garden of the city of Covilhã and will be limited to the park's enclosure. It is also necessary to take into account the ease of accessibility and vandalism of the equipment, the identification of critical and risk points and potential slip zones. It was necessary to choose a location that was contained in a semi-enclosed system, in which it is possible to determine the installed power, the water net head and the available flow between both reservoirs located in the enclosure.

The impact on the infrastructures: Due to the weak state of both reservoirs and to neutralize the impact on the existing water system, it was necessary to establish a maximum diameter and flow pressure for the new pipes to be installed.

The indispensable outputs of the system: Since the prototype is adapted to the public water supply service, there are essential outputs, such as the consumption of water from the population (which cannot be compromised) and the energy consumption associated with the system to supply public tanks or other on-site energy devices).

The operating mode: Under ideal conditions, the operating mode is defined as follows: by day: The produced solar and wind energy are used to supply the pump and store hydric potential in the upper reservoir and to supply an existing recirculation water pump in the park. At night: PAT (Pump as Turbine) produces sufficient energy to meet the energy needs of the park. The surplus energy will be stored in batteries. The main water supply line cannot be compromised. This mode of operation of the integrated energy system will be redefined throughout its analysis and operating time, according to the following factors:

- The stochastic nature of energy sources;

- the stochastic nature of water consumption;

- the storage capacity of both reservoirs to increase hydric production and,

- the technical specifications/modifications suggested by the remaining EdGeWiSe project partners during the project execution time.

Legislation: For the integrated system to function without complications of any kind, it is necessary to review and analyze the existing legislation.

Financial constraints: Restrictions on financing are the most important in the development and installation of prototypes in the context of Living Labs and in real scale. The whole implementation process will have to take into account the available funding.

Social and environmental: The OECD (Organization for Economic Co-operation and Development) pointed to the need for changes in the management of cities, with the adoption of participatory intervention strategies to reduce environmental conflicts and reduce the effect of pollution on nature. Lately, companies are poised to gradually take a leading role in city management and negotiations have been conducted for collective well-being to the detriment of the individual priorities of the involved actors in the negotiations. The purpose of the prototype installation is to analyze the social and environmental constraints that it entails. 


\section{PRototype Configuration}

The development and implementation of hybrid systems require a decision support system (DSS) that takes into account economic, environmental and social factors as well as energy management actions, possible system states and operational modes of the system in order for the integration among all components is reflected in the efficient and optimized management of water and energy systems.

The DSS aims at supporting all the phases of a typical decision-making process (workflow) and delivers the following Services:

- The Design of alternative configurations for a specific case, in terms of feasibility, technical performance and economic viability.

- The Assessment of economic, environmental and social performance for alternative configurations.

- The Evaluation of the alternative configurations and the selection of the appropriate system and implementation plan, involving managers and experts in the process of evaluation.

Due to the number of variables and constraints involved in the prototype development, the configuration of the integrated management system to be installed is extremely complex. Of a total of 96 considered scenarios, 56 are feasible. It was considered relevant to analyze all the different scenarios in order to choose the most appropriate one. Among the analyzed sets of variables, we considered: hydroelectric power generation equipment, the number and type of pipelines to be installed and devices to be supplied. After analyzing the terrain through maps, satellite photos and, in the case of this study, existing water consumption data and the characteristics of the site, which involves identifying and recognizing five main additional variables: useful net head, available flow, orientation of the solar radiation and the intensity and direction of the wind, this dependence and synergy will influence the whole process of the prototype development and design - from the first estimates of the produced energy until the choice of equipment to be installed relatively to hydroelectric, solar and wind energy. Fig. 3 shows the sketch of the integrated water, solar and wind energy system for the pre-selected location. Among the analyzed scenarios, A3B3 was chosen, which from the point of view of research, is the solution that allows studying more scenarios and combinations of interest to the object of study. The chosen solution is defined by an installation of two new pipelines. One of them, will have the direction opposite to the gravitational flow connected to a pump operating in the normal mode to store hydric potential in the upper reservoir. The second pipeline is complemented with a PAT (Pump as Turbine) and a conventional hydraulic turbine to compare the results between the devices. The main objectives of the responsible team for the installation and operation of the prototype are: Implement, supervise, correct and manage all the variables, scenarios and restrictions involved throughout the execution and analysis of the project; optimize the integrated system installed in the park in terms of energy and water; analyze the technical aspects and specifications of applied instrumentation; optimization of PAT production and to modify and correct any specification on the operating mode as needed.

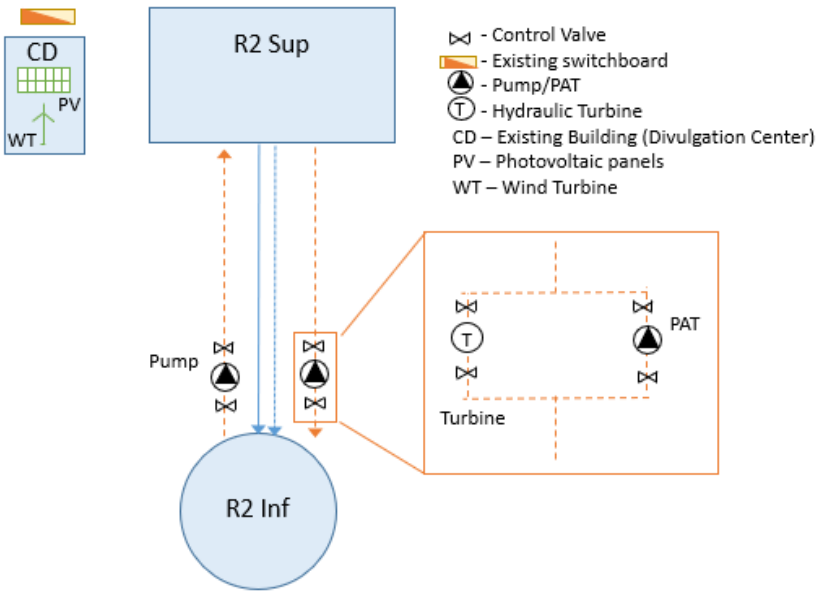

Fig. 3: Integrated Energy and Water system to implement in Alexandre Aibéo Park (Botanical Garden) - chosen solution, A3B3.

\section{MONitoring AND SUPERVISION OF THE SySTEM}

The integration and management of integrated systems, from the ideal point in regard to the operation mode, requires real-time information complemented with forecast model data. This information can serve many purposes, allowing the intelligent management of the integrated water and power distribution system to reach its maximum potential in production and consumption. For wind energy production, known parameters are required, namely wind direction and wind speed. In the case of photovoltaic energy, solar irradiance and temperature are relevant parameters. The level of water inside the reservoirs must be known in real time to efficiently store the produced energy from renewable sources as a potential of gravitational energy. One of the most important factors is the main function of the water distribution network - to provide water to end consumers. To avoid any service disturbance, the water pumping from the lower level to the upper-level reservoirs must be done in a way that ensures the continuity of the service.

In parallel, the wireless sensor network (WSN) registers specific characteristics and physical access to ground nodes, meeting all the safety requirements. WSN-based solutions should follow the international standardization that has been taking place in the field of intelligent metering, which allows increasing the integration potential for energy and water systems. Connecting a battery-powered WSN will require a periodic maintenance service to replace them, which is impractical if the number of sensor nodes is large and hardly accessible. By collecting energy from the integrated system to be installed and the surrounding environment (mainly from vibrations, thermal gradients, daylight radiation or microbial fuel cells), the WSN becomes energetically independent [13].

\section{CONCLUSIONS}

A review study on the water-energy nexus, including an antecedent framework and its approach in a combined form, has been made up to the present phase of the work and international project in which this document is inserted (Project EdGeWiSe - Energy and Water Systems Integration and Management), with an included discussion of its challenges and associated opportunities. The development of 
the nexus concept in an urban context was studied and a real space was identified to analyze the optimization of an integrated management system. The study was initiated involving three variables, the production of electricity through mini-hydro, mini-solar and mini-wind, and the simultaneous consumption in a stochastic environment. The work will be further developed using a mathematical formulation of the problem, simulation systems and the implementation of a WSN (wireless sensor network) that will collect information from the pilot to be installed to determine the optimum operating point. With the described system, it is possible to analyze the environmental and economic impacts of the system while simultaneously promoting efficiency and reliability. The annual production of energy will have to exceed the annual energy consumption. In its total, it must at least equalize the sum of the total consumed energy, also taking into account all technical losses that will occur in the storage system, AC-DC-AC conversion and transport (this latter factor may not be included since the production system will be very close to consumers). The importance of neutralizing the environmental, social, and infrastructure impact is also one of the main concerns of this study case.

\section{ACKNOWLEDGMENT}

The authors would like to thank the Foundation for Science and Technology (FCT) for the financial support (Grant ERANETMED/0004/2014), at the initiative of the ERANETMED member states, the associated countries, the Mediterranean partner countries (Project ID eranetmed nexus-14- 044), the Department of Electromechanical Engineering and C-MAST - Center for Aerospace Science and Technologies, of University of Beira Interior.

\section{REFERENCES}

[1] International Energy Agency, "World Energy Outlook 2012," Paris, 2012.
[2] Commission of the European Communities, Living Labs for Userdriven Open Innovation - An overview of the living labs methodology, activities and achievements, Vols. \%1 de \%2ISBN 978-92-79-10358-2/DOI 10.2759/34481, Luxembourg: Information Society and Media DirectorateGeneral, 2009.

[3] European Network of Living Labs, "What is a Living Lab?," [Online]. Available: http://enoll.org/about-us/. [Acedido em 28 March 2018].

[4] UNESCO, “The United Nations World Water Development Report 2014: Water and Energy," United Nations World Water Assessment Programme, Paris, 2014.

[5] UNIDO (United Nations Industrial Development Organization), "Policies for Promoting Industrial Energy Efficiency in Developing Countries and Transition Economies," Vienna, 2008.

[6] WEC - World Energy Council, "Water for Energy," London, 2010.

[7] UNESCO, "Water for a Sustainable World," Paris, 2015.

[8] International Energy Agency and OECD, "World Energy Outlook," Paris, 2013.

[9] The World Bank, "Thirsty Energy," Washington: Water Unit, Transportation, Water and ICT Department, Sustainable Development Vice Presidency, 2013.

[10] P. S. A. Espírito-Santo, "Harvesting Energy from Microbial Fuel Cells: Powering Wireless Sensor Networks Operating in Wastewater Treatment Plants," Biologically-Inspired Energy Harvesting through Wireless Sensor Technologies, IGI Global - Disseminator of Knowledge, pp. 121-171, 2016.

[11] M. Z. Jacobson and M. A. Delucchi, "Providing all global energy with wind, water, and solar power, Part I: Technologies, energy resources, quantities and areas of infrastructure, and materials," Energy Policy, vol. 39 (3), 1154-1169, 2011, doi:10.1016/j.enpol.2010.11.040.

[12] M. A. Delucchi and M. Z. Jacobson, "Providing all global energy with wind, water, and solar power, Part II: Reliability, system and transmission costs, and policies," Energy Policy, vol. 39 (3), 1170-1190,2011, doi:10.1016/j.enpol.2010.11.045.

[13] A. Silva, A. Espírito-Santo, F. Santos, J. Páscoa, C. Fael, "WaterEnergy Nexus: Review of Literature in Management of Integrated Systems, Challenges and Opportunities. Case Study in Urban Contex", ICEUBI2017 - International Congress on Engineering, 2017.

[14] "Project Summary", EdgeWise - Energy and Water Systems Integration Management. [Online]. Available: http://edgewise.ubi.pt/index.php/en/presentation. [Accessed: Jul. 4, 2018]. 